\title{
O agir simbólico corpo-vocal na Composição Poética Cênica
} Body-vocal symbolic action in Scenic Poetic
Composition

Heitor Martins Oliveira ${ }^{1}$

Juliano Casimiro de Camargo Sampaio ${ }^{2}$ 


\section{Resumo}

O artigo discute o processo de criação de "Ninguém matou Suhura", espetáculo teatral inspirado na obra literária homônima da escritora moçambicana Lilia Momplè. A Composição Poética Cênica, perspectiva adotada para a construção deste espetáculo, almeja a construção de um universo de ações simbólicas pautadas em um contexto cotidiano compartilhado entre artistas e fruidores. A discussão das composições corpo-vocais que constituem a partitura do espetáculo aborda as qualidades de movimento (Laban, 1978) e o papel da voz e do coro na criação musical para o teatro (Tragtemberg, 1999). Reflexões mais abrangentes sobre a perspectiva estética adotada e a formação do sujeito-ator no contexto do processo de criação pautam-se no conceito de agir simbólico (Boesch, 1991) em psicologia construtivista semiótico-cultural e nas proposições sobre a dimensão sensivel das relações eu-mundo (Merleau-Ponty, 2011; 2012; 2013) em filosofia cultural. Esta pesquisa teórico-empírica levou-nos a compreender a composição poética (corpo-sonora) cênica como um processo colaborativo que opera o campo estético a partir de qualidades de movimentos corporais e vocais e elabora nexos teatrais fundados em texturas imagético-sonoras polifônicas. As experimentações resultantes fazem emergir novos processos de construção pessoal de conhecimento, que potencializam novas dinâmicas de criação pessoal e coletiva.

Palavras-chave: Composição Poética Cênica; criação corpo-vocal; construção de conhecimento

\section{Abstract}

This paper discusses the creation process for "Ninguém matou Suhura", theatrical spectacle inspired by the eponymous literary work by Mozambican writer Lilia Momplè. Poetic Scenic Composition, approach chosen for the construction of this spectacle, aims to build a universe of symbolic actions based on an everyday context shared between artists and public. The discussion of body-vocal compositions that constitute the score of the spectacle addresses the qualities of movement (Laban, 1978) and the role of the voice and the choir in musical creation for the theater (Tragtemberg, 1999). Broader reflections on the aesthetic perspective adopted and the formation of the subject-actor in the context of the creation process are guided by the concept of symbolic action (Boesch, 1991) in constructivist semiotic-cultural psychology and the propositions on the sensitive dimension of self-world relations (Merleau-Ponty, 2011; 2012; 2013) in cultural philosophy. This theoretical and empirical research led us to understand the poetic (body-sound) scenic composition as a collaborative process operating the aesthetic field from the qualities of body and vocal movements and elaborating theatrical links founded in image-sound polyphonic textures. From the resulting trials, new personal knowledge construction processes emerge, which power new dynamics of personal and collective creation.

Keywords: Poetic Scenic Composition; body-vocal creation; knowledge construction

ISSN: 1414.5731

\footnotetext{
${ }^{1}$ Universidade Federal do Tocantins (UFT). Prof. Assistente Ms. Palmas, TO, Brasil. heitor oliveira@uft.edu.br
}

2 Universidade Federal do Tocantins (UFT). Prof. Dr. Palmas, TO, Brasil. juliano.casimiro@uft.edu.br 
Esta pesquisa emergiu no contexto da montagem do espetáculo teatral "Ninguém matou Suhura". Trata-se de uma das ações do projeto de extensão universitária "Corpo, Narrativa e Significação - diálogos entre a criação corpo/vocal e o desenvolvimento humano", desenvolvido junto à Universidade Federal do Tocantins, sob coordenação dos autores deste artigo. O objetivo do projeto foi estruturar atividades de articulação entre Composição Poética Cênica (Sampaio, 2014) e desenvolvimento humano. As investigações cênicas foram acompanhadas de reflexões teóricas na fronteira entre três áreas do conhecimento: as artes, a filosofia cultural e a perspectiva construtivista semiótico-cultural em psicologia. O espetáculo é uma construção acional imagético-sonora proveniente da experimentação de situações reais da dominação portuguesa em Moçambique, descritas pela autora Lilia Momplè, em obra literária homônima à criação cênica de que trata este texto.

A Composição Poética Cênica, perspectiva adotada para a construção do espetáculo, busca o contínuo trânsito bidirecional entre o agir concreto sobre materialidades, tanto corporais quanto de objetos, e a ação abstrata, para evocação de materialidades ausentes no espaço de representação. Para tanto, todos os elementos técnico-artísticos, tais como iluminação, sonoplastia, indumentárias e cenografia são operados pelos atores-compositores de dentro da cena e em tempo real. Almeja-se, com isso, a construção de um universo de ações simbólicas características daquele contexto específico, mas que estão pautadas em e aludindo a um contexto cotidiano compartilhado entre artistas e fruidores. Predominantemente, o trabalho está voltado para o coro cênico.

Nesse contexto, o que apresentamos aqui é uma discussão a respeito do processo de composição corpo-sonora da construção imagético-acional de um espetáculo teatral que não pretendeu a elaboração de qualquer fábula, mas sim a atuação no campo sensível e simbólico de construção e significação de uma obra de arte efêmera, tomando esse processo como formador do sujeito-artista.

Assim, objetivamos neste artigo responder a duas questões; 1- no âmbito da criação artística: como fazer emergir das diferentes materialidades corpo-sonoras de artistas-pesquisadores composições com qualidades estéticas que sejam em si mesmas teatrais, sem a necessidade da construção de um nexo semântico de sentido para a cena teatral? 2- no âmbito da formação pessoal do artista: como as dinâmicas de composição corpo-sonora podem potencializar processos pessoais de construção de conhecimento?

Quatro universos teóricos balizaram as tentativas de respostas a essas questões: Boesch (1991); Laban (1978); Merleau-Ponty (2011; 2012; 2013); e Tragtemberg (1999). Ainda que não discutamos detidamente cada uma das contribuições acima, por questões de recorte e espaço, alertamos ao leitor que o ciclo metodológico sob o qual se deu esta pesquisa artístico-científica inclui deliberadamente cada uma dessas obras, a partir de discussões teóricas e investigações prático-laboratoriais. 


\section{Metodologia}

Pautamo-nos nesta investigação teórico-empírica no método qualitativo de pesquisa, tendo os pesquisadores como participantes (Simão, 1992). O que estruturamos é um ciclo ininterrupto experimentação prática - questionamento - reflexão teórica - novas experimentações práticas, que levaram ao resultado estético do espetáculo teatral "Ninguém matou Suhura".

Nosso foco nesta pesquisa está no trabalho de composição corpo-sonora para a construção de imagens cênicas complexas que tomam o corpo e suas sonoridades como significantes fundantes de qualquer sentido afetivo-cognitivo a respeito da obra de arte teatral. Nesse sentido, o sujeito da nossa pesquisa é o artista-pesquisador-compositor.

Os participantes da pesquisa são, em sua maioria, estudantes da Licenciatura em Teatro da Universidade Federal do Tocantins, e funcionárias da Secretaria da Educação e Cultura do Estado do Tocantins. Entre essas últimas, a formação universitária varia entre Teatro, Música e Educação Física. Heitor Martins Oliveira é encenador do espetáculo em questão e Juliano Casimiro de Camargo Sampaio é diretor musical.

Os dados que ilustram e adensam a reflexão teórica aqui realizada são provenientes dos cadernos de campo dos pesquisadores e de descrições a posteriori de cenas do espetáculo. Essas descrições, dada a natureza do material empírico, representam recortes pontuais de uma situação imagético-sonora mais ampla. Entretanto, evitamos a descrição completa das cenas, dado o recorte teórico deste trabalho e o espaço disponível para discussões.

\section{Resultados e discussão No âmbito da criação}

Em nosso trabalho, mais que o uso de vozes como fonte sonora para execução de ideias musicais, o canto se constituiu como ação simbólica no espaço cênico. A textura sonora do espetáculo foi construída no interior desse espaço, por meio do canto e outras ações com implicações acústicas, tornando a composição sonora indissociável do processo dinâmico de composição poética cênica. Esse processo, no contexto em que estamos trabalhando, significa a busca por um nexo de sentido para a criação cênica que não esteja pautado pelo seu valor semântico, senão pela disposição relacional de diferentes materialidades concretas, simbólicas e sonoras, apresentadas ao fruidor (espectador) como uma qualidade relacional contextual e cênica, fruto de ações simbólicas dos artistas envolvidos.

O que queremos dizer é que a qualidade estética do jogo imagético-acional de cada cena não pode ser reconhecida no ser-ator ele mesmo, tampouco nos objetos cênicos, ou ainda nos componentes técnico-artísticos da encenação: iluminação, figurino, maquiagem, sonoplastia etc.. Ela se configura na periferia de todas essas coisas ao mesmo tempo. Ela é uma periferia qualitativa compartilhada entre toda e qualquer materialidade que se tenha na cena, seja ela concreta ou não (Sampaio, 2014, p. 29). 
Nos primeiros exercícios musicais-vocais desenvolvidos junto aos participantes do projeto foram exploradas vocalizações e movimentações que permitiram intuir possibilidades sonoras e rítmicas acessíveis ao grupo. A observação das extensões vocais individuais e das qualidades sonoras do canto coletivo em vocalises e pequenas células melódicas foi o ponto de partida para a seleção de uma tessitura, do espaço tonal e para a classificação de registros vocais. Esses elementos, consolidados ao longo do processo de composição, podem ser verificados no Figura 1.

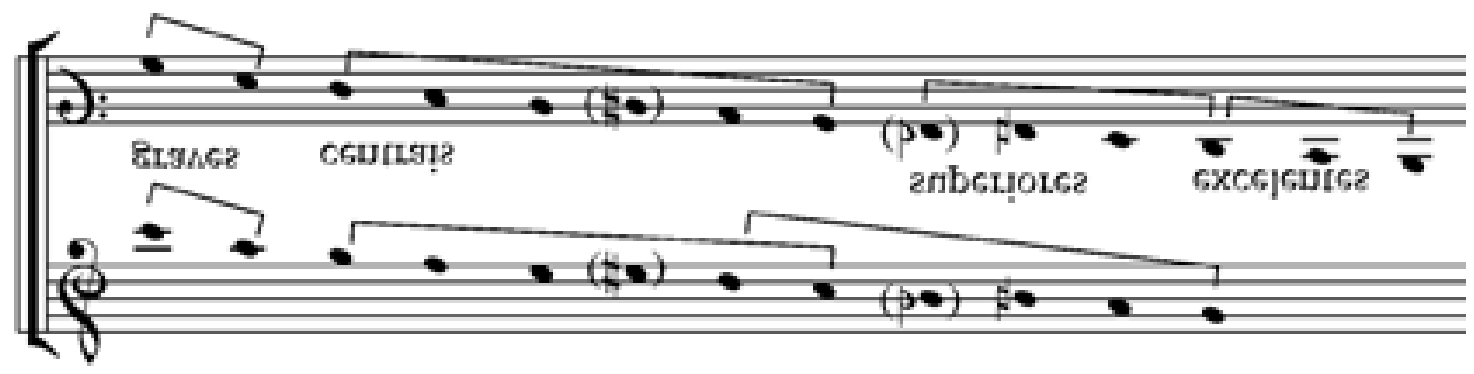

Figura 1: tessitura vocal, registros e espaço tonal selecionados para a composição dos coros do espetáculo "Ninguém matou Suhura"

A classificação dos registros remete às qualidades sonoras observadas na vocalização coletiva do elenco durante o processo de preparação vocal, considerando suas potencialidades, e, portanto, um campo possível de ação simbólica, para a composição cênico-musical. A diferenciação na classificação entre vozes femininas e masculinas destaca a percepção de uma qualidade peculiar de mudança de registro da região central para a região superior das vozes femininas, qualidade essa que adquiriu relevância no processo de criação, dado o espetáculo estar majoritariamente voltado para o universo da dominação portuguesa e masculina sobre mulheres moçambicanas. A ênfase nas qualidades sonoras foi complementada com a resolução, adotada também no estágio inicial, de não utilizar textos para a composição dos coros.

O trabalho de direção musical procedia a partir da elaboração prévia de células ou frases melódicas suscetíveis a operações sob dois critérios principais. O primeiro é a exploração e seleção de diferentes registros, embocaduras (boca chiusa, vogais ou sílabas neutras) e impostações ou ressonâncias. O segundo, a combinação das frases de maneira sequencial e/ou simultânea para criação de texturas harmônicas, contrapontos ou polirritmias. Ou seja, os coros foram realizados como sucessões ou sobreposições de ostinatos vocais. Tais realizações ocorriam durante os ensaios, quando as decisões sobre qualidades sonoras, durações e texturas concretizavam a composição vocal de ações simbólicas para o espetáculo, na medida em que compunham junto com as iniciativas físicocorporais qualidades estéticas coerentes com o todo das proposições cênicas.

Desde essa perspectiva, e do ponto de vista da composição musical, "a música de cena coloca questões específicas que apresentam novas relações que só podem ser abordadas em seus contextos próprios" (Tragtemberg, 1999, p. 16), essencialmente diversos da música dita "pura" e mesmo do drama musical. Reiteramos que o processo de criação de "Ninguém matou Suhura" caracterizou-se 
pela convergência dos procedimentos de elaboração de ações vocais e corporais que constituem a partitura cênico-musical do espetáculo.

Improvisações instrumentais e sons gravados e processados eletronicamente, elementos explorados em sucessivas aproximações à composição sonora do espetáculo, foram gradativamente perdendo espaço frente às relações poéticas pautadas no agir simbólico corporal. As vocalizações coletivas foram assumidas como materialidade sonora primordial e continuamente elaborada e reelaborada frente aos nexos de sentido estético-cênico. Como salientava Tragtemberg (Ibidem, p. 144), "deve-se notar que o uso de vozes na música de cena sempre estabelece uma relação mais direta com o espectador, uma vez que coloca a textura sonora em escala com a sua dimensão".

$\mathrm{Na}$ abordagem escolhida, a concepção de compositor de música de cena, responsável por uma espécie de "tradução sonora" (Ibidem, p. 37) ou de resolução musical do conceito estético do espetáculo (Ibidem, p. 169), necessariamente deve dar lugar à concepção de criação cênico-musical colaborativa. Os eixos básicos comuns do conjunto polifônico resultante, "densidade dos eventos, velocidade e tempo", não são apenas fixados como estruturação do projeto cênico (Ibidem, p. 25), mas (co)criados de forma integrada.

De maneira mais específica, composições corpo-vocais foram estruturadas a partir de sequências de movimentos ou ritmos. De acordo com o pensamento de Laban (1978, p. 195, grifos dos autores), na organização de sequências de movimentos, o ritmo é composto de diversos elementos: "Podem-se discernir ritmos-espaço, ritmos-tempo e ritmos-peso. Na realidade, estas três formas de ritmo sempre estão associadas, apesar de uma delas poder ocupar lugar de destaque em uma dada ação".

Os ritmos-espaço referem-se ao desenrolar sucessivo de direções em constante mudança e a formas que são produzidas pela simultaneidade de ações. Os dois aspectos são análogos, na música, aos elementos de construção tonal: melodia e harmonia (Ibidem). Os ritmos-tempo podem ser analisados em termos de sua velocidade (andamento), durações relativas de cada parte do movimento e grau de regularidade, podendo ser métricos ou livres (Ibidem, p. 196-197). Finalmente, os ritmos-peso referem-se aos padrões de acentuação de uma sequência de movimentos (Ibidem, p. 198). Os aspectos analisados por Laban com relação aos ritmos-tempo e ritmos-peso aplicam-se às ações corporais e vocais.

Além das questões pertinentes à estruturação de sequências, o sistema de Laban dá conta de qualidades mais gerais dos movimentos. Nesse caso, abordam-se atitudes corporais analisadas a partir de quatro fatores - peso, espaço, tempo e fluência - os quais resultam em qualidades de movimento de relaxada a enérgica (peso), de linear a flexível (espaço), de curta a prolongada (tempo), de liberta a controlada (fluência) (Ibidem, p. 114). Quanto aos movimentos vocais, essas atitudes remetem a qualidades discutidas acima, tais como registro vocal, ressonância e densidade, além de outras como dinâmica e articulação (legato, staccato etc.).

Na composição imagético-sonora de "Ninguém matou Suhura", as sequências corporais e vocais foram compostas de maneira ora sincrônica, ora assin- 
crônica. Dessa forma, pode-se falar em um conjunto polifônico cênico-musical.

Tomemos agora uma cena do espetáculo como exemplo do que vimos apresentando.

O segundo movimento cênico se refere a uma passagem da obra de Lillia Momplè em que uma moçambicana é estuprada e morta por um português. Na passagem literária, a ação, que começa como um envolvimento mútuo e com aceitação deliberada, acaba em violação agressiva. Esse trecho está mesclado, no espetáculo, com a constatação também apresentada pela autora em sua obra de que a prostituição era a única opção de sobrevivência para algumas mulheres naquele contexto.

No espetáculo, a construção gradativa da aceitação ao estupro foi concebida da passagem de uma valsa coreografada para uma tentativa de imobilização da mulher no chão. A valsa inicia com passos clássicos, ao som de uma frase melódica apresentada pelas vozes masculinas, que se utilizam de uma combinação de sílabas neutras para construir a articulação musical característica do gênero (Figura 2).

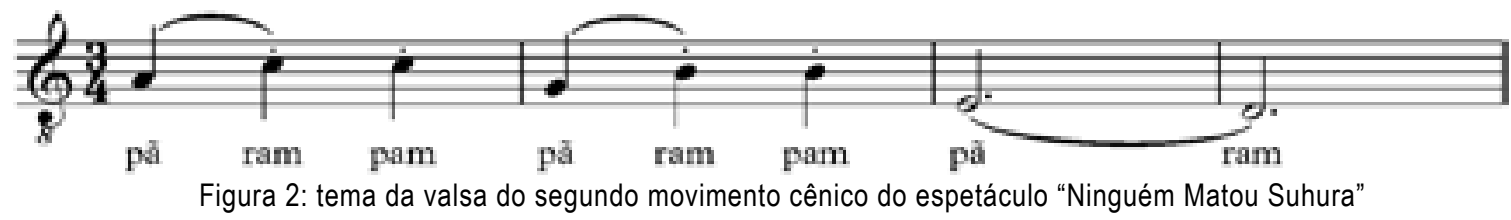

Essa frase melódica é imediatamente repetida, apresentando-se como ostinato. O parceiro que dança com a atriz é trocado a cada repetição, até que todo o elenco masculino tenha dançado com ela. $O$ ator mais alto começa a dança com a atriz mais baixa do elenco. Cada homem que substitui o anterior na dança/estupro é menor que o anterior. Três outros ostinatos (Figura 3), entoados por três grupos de vozes femininas, são gradativamente acrescentados à textura, até que se construa um contraponto a quatro vozes.

$\mathrm{Na}$ medida em que um novo homem chega para a dança, a coreografia da valsa vai desaparecendo paulatinamente e a dominação masculina emerge na cena. Ao todo, cinco homens "dançam" com a atriz, como referência à prostituição. Quando o quinto ator chega para "dançar", sua função é conseguir imobilizar completamente a atriz no chão. Nesse ponto, a textura vocal polifônica já atingiu seu ápice caracterizando-se pela repetição de um ciclo harmônico suspensivo (Sol Maior: IIm - I - IIm7 - V) e pela sobreposição de qualidades sonoras e fraseados resultantes dos diferentes registros, articulações e padrões de acentuação inerentes a cada ostinato. As etapas de imobilização não são coreografadas ou combinadas anteriormente. Os atores devem efetivamente realizar o ato em tempo real e segundo o jogo que estabelecem com a atriz. Embora a sincronia de ações corporais e vocais se dissolva ao longo do movimento cênico, a música assume a função de delimitar a duração e o jogo se encerra simultaneamente à sétima repetição da célula melódica entoada pelo elenco masculino. 

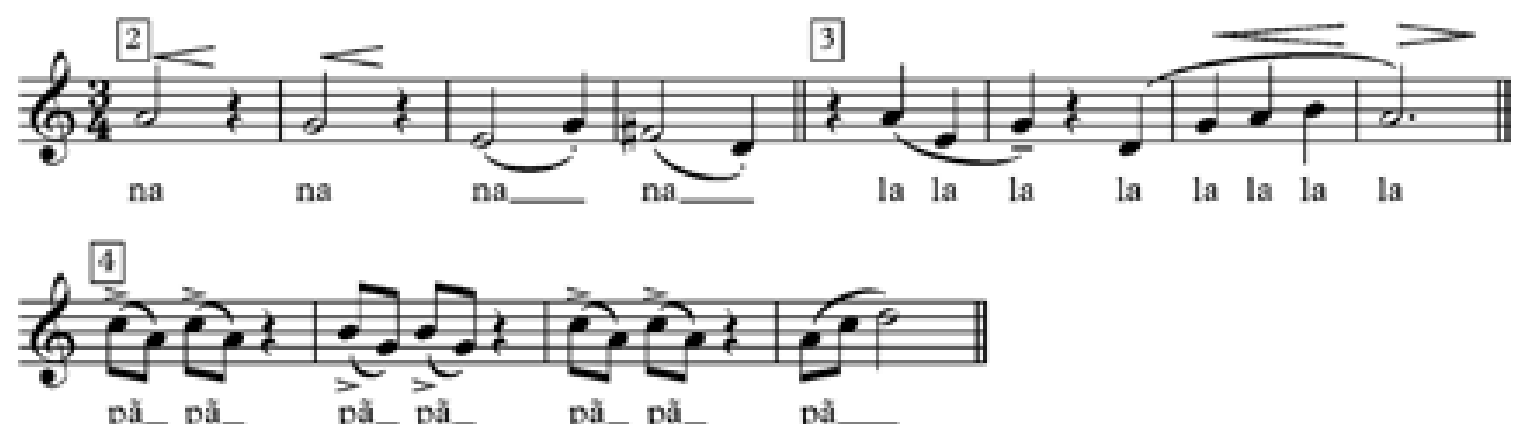

Figura 3: os três ostinatos entoados pelas vozes femininas no segundo movimento cênico do espetáculo "Ninguém matou Suhura"

Todavia, devemos atentar para o fato de que o campo da materialidade sonora se instaura no espetáculo já em sua abertura, quando o coro inicial desvela gradativamente o espaço tonal, qualidades rítmicas e qualidades sonoras que estarão presentes em toda a obra. Passa-se rapidamente de um estado de suspensão harmônica e de negociação das durações (Figura 4) para a apresentação sucessiva de diversas células e variantes melódicas, oposições entre texturas (solo, todo o grupo, apenas vozes femininas) e uma gama de intensidades, articulações e impostações vocais.

Associando-se esses elementos à negociação e apresentação também gradativa de ações corporais coletivas e eventualmente coreografadas, o primeiro movimento cênico caracteriza-se pela construção do espaço simbólico compartilhado no qual o espetáculo se desenrola. Dessa maneira, o contato com o fruidor é estabelecido nas bases de uma proposta cênica calcada no agir simbólico corpo-vocal, uma vez que o coro "nos distancia do devir temporal cronológico, estabelecendo uma irremediável ruptura com qualquer forma de ilusionismo dramático" (Tragtemberg, 1999, p. 142).

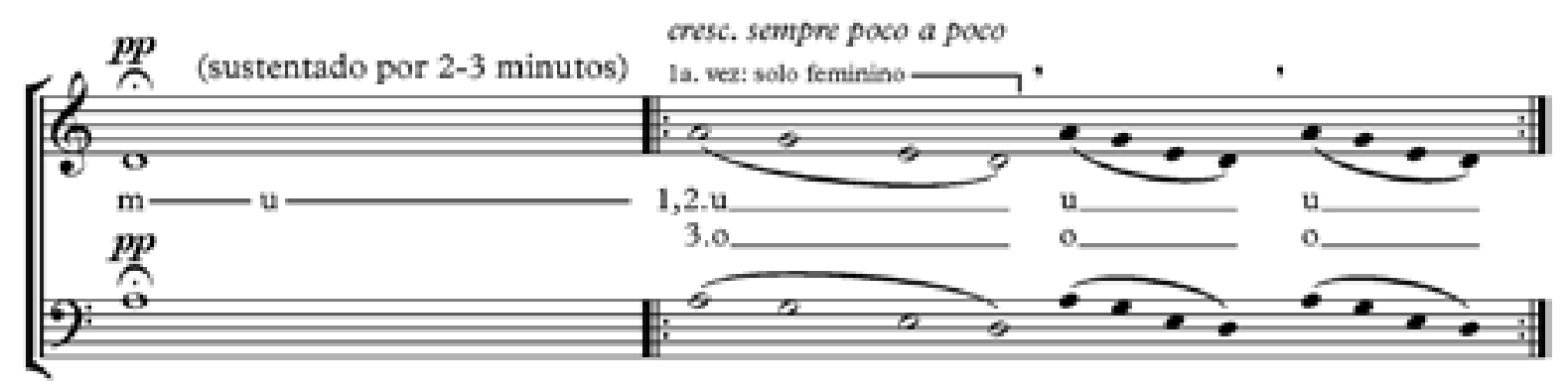

Figura 4: preâmbulo do coro do primeiro movimento cênico do espetáculo "Ninguém matou Suhura"

Concomitantemente, há nesse primeiro movimento um caráter de abertura, no sentido de antecipação das diversas experiências a serem apresentadas ao fruidor ao longo da obra, levando-se em conta que "as diferentes texturas vocais, desde a voz solo passando pelo grupo de câmara até o grande coral, provocam impactos sonoros e emocionais diferenciados no espectador" (Ibidem, p. 141). Os cantos apresentados posteriormente, inclusive a valsa do segundo movimento cênico discutida acima (Figuras 2 e 3), são variações e desdobramentos das ideias musicais introduzidas já na abertura do espetáculo.

Essa breve análise que realizamos nos permite, neste contexto, concluir que, dentro da nossa proposta de composição, as materialidades corpo-sonoras 
são mais eficazes quando apresentadas aos poucos ao fruidor, e quando, na medida em que são trazidas à cena, realizam entre si fricções acionais-simbólicas, a partir de 3 categorias temporais: 1- repetição (diferentes contexto e modos de apresentação de um mesmo elemento); 2- duração (elemento que dura um lapso de tempo específico deliberado); 3 - persistência (elemento que sofre significativas transformações para transitar entre um contexto e outro e se manter constantemente presente) (Sampaio, 2014).

\section{No âmbito dos processos de construção de conhecimento}

Os caminhos adotados para trabalharmos a emergência das composições poéticas-cênicas estiveram, a todo momento, pautados pela tentativa de responder de modo prático à segunda questão que organiza estes escritos, a saber: como as dinâmicas de composição corpo-sonora podem potencializar processos pessoais de construção de conhecimento? O conhecimento a que nos referimos aqui se configura como a capacidade do artista de supor situações diferentes daquela apontada pela concretude das relações, bem como o reconhecimento pessoal de que se possui sempre um poder finito de ação sobre o mundo, entretanto, plausível de transformação.

O agir simbólico, a partir de Boesch (1991), e como o adotamos para fins desta pesquisa, está pautado pela ideia de que o sujeito está sempre inserido em um campo cultural compartilhado, que the permite determinado conjunto de ações e atitudes e impossibilita outros. $O$ agir a que nos referimos na exploração cênica, como o todo da existência acional do sujeito, comporta uma dimensão denotativa e outra conotativa. Essa dimensão denotativa, como exploração real e concreta das materialidades dispostas em cena, é assumida como disparadora das nossas investidas cênicas. O trato concreto com as materialidades impulsiona qualidades específicas de futuridades da relação cênica que se pretende levar ao fruidor. Adicionada àquela, a dimensão conotativa é assumida como polivalente: se, por um lado, a significação deriva desse universo cultural compartilhado, por outro, ela emerge da vida privada dos sujeitos que operam a ação.

A ação simbólica configura-se como uma exploração deliberada da "constelação de qualidades" de uma determinada materialidade, a partir das negociações de sentido de existência da coisa, desde a exploração motora, seus sentidos compartilhados de existência e a significação pessoal atribuída. Enquanto a existência denotativa da coisa para a pessoa implica em separar aquela materialidade do todo (ainda que seja uma existência em relação), a dimensão conotativa polivalente resguarda para a coisa a obrigatoriedade de ser percebida como parte de um todo maior, que existe histórica e pessoalmente em relação a outras materialidades, tanto por cooperação e concordância, quanto por contraposição e discordância. Nesse contexto, o trabalho do ator está fortemente centrado na capacidade de reconhecer uma "disposição" simbólica das materialidades para os fins de sentido, que pode ser afetivo, na direção desejada por ele. As experimentações que realiza, portanto, são sempre referidas a uma futuridade cênica almejada e partem de um passado de experimentações cênicas e cotidianas que the permitem o trabalho no âmbito da analogia. 
Nessa direção, e em intenso diálogo com as proposições de Merleau-Ponty (2011; 2012; 2013) sobre a dimensão sensível das relações eu-mundo, investimos corporalmente na experimentação motora do mundo. Cada materialidade (seja um objeto ou o corpo de outro autor) trazida ao jogo cênico era explorada em sua atualidade material. Na sequência, algo da coisa que capturasse o ator deveria ser explorado por ele no âmbito da virtualidade, do movimento abstrato, por exemplo. Ou seja, ainda que partíssemos da concretude das relações, almejávamos a emergência de um universo simbólico (co)construído e compartilhado a partir dessa dimensão atual da coisa, mas que só existisse na medida em que fizesse ver junto de si o contexto de seu nascimento.

A atualidade dos objetos e dos corpos assumia, assim, uma dupla função: como disparadora das experimentações em criação e, após as investigações pessoais-virtuais sobre a coisa, o resultado que se pretendia levar a público. Como dissemos anteriormente, essa segunda atualidade não pressupunha nexo semântico. Nesses termos, a passagem da atualidade para a virtualidade e a configuração de outra atualidade caracterizava, respectivamente, a compreensão do nexo semântico disparador das criações, a exploração simbólico-pessoal deste nexo e a emergência de um nexo sensorial atrelado ao resultado estético da obra, enquanto um emaranhado de movimentos abstratos. Isto porque, segundo Merleau-Ponty (2011, p. 160),

O movimento abstrato cava, no interior do mundo pleno no qual se desenrolava o movimento concreto, uma zona de reflexão e de subjetividade, ele sobrepõe ao espaço físico um espaço virtual ou humano. O movimento concreto é, portanto, centrípeto, enquanto o movimento abstrato é centrífugo; o primeiro ocorre no ser ou no atual, o segundo no possível ou no não-ser; o primeiro adere a um fundo dado, o segundo desdobra ele mesmo seu fundo.

Tanto o movimento concreto como o movimento abstrato está implicado por uma ação imaginativa (Sampaio, 2014). Essa ação imaginativa se configura em uma dupla dimensão: Imaginação retrospectiva, em que o ator se pauta na historicidade da sua relação com a coisa para supor como esta mesma relação deveria ser; Imaginação prospectiva, em que o ator, a partir da emergência do contexto, supõe contornos diferentes para sua relação com a coisa, agindo no âmbito do poderia ser.

Este trânsito entre o dever ser e o poder ser é parte daquilo que faz emergir o novo a partir do familiar. Segundo Boesch (1991), nossas ações, incluindo-se aí aquelas destinadas à criação artística, estão sempre referidas a uma esfera de ação familiar (co)construída com as pessoas que ocupam um espaço na nossa cotidianidade. Ainda segundo o autor, somente em coordenação, comparação ou referência a essa esfera familiar de ação é que sentimos a sensação de segurança para lidar com algo que nos parece não-familiar. É nesse contexto e pela radicalização do pensamento boeschiano que decidimos por partir sempre da concretude das relações em direção à atualidade abstrata e sensível dessas mesmas relações. 
A emergência daquilo que na relação pode ser diferente do que a historicidade aponta, o que muitas vezes configura-se como não-familiar, é validado como útil e viável no contexto da criação e pelo ator, na medida em que atende a intenções motoras e simbólicas do criador em relação à circunvizinhança que caracteriza a obra teatral. Ou seja, o ator percebe-se a si como uma qualidade possível e satisfatória de presença relacional evidenciada pelos modos como interage com as coisas no trânsito atualidade-virtualidade-atualidade. Tudo aquilo que o ator deixa ver das suas relações com as coisas, revela parte do seu poder de ação sobre o mundo, já que esse mesmo poder deriva do modo mutável como ele se permite ser atraído por esse mesmo mundo. Para Merleau-Ponty (2013, p. 80), a partir de Malraux,

[...] a percepção já estiliza. Uma mulher que está passando não é de início para mim um contorno corporal, um manequim colorido, um espetáculo; é "uma expressão individual, sentimental, sexual", é uma certa maneira de ser carne dada por inteiro no andar ou mesmo no mero choque do salto do sapato no chão, como a tensão do arco está presente em cada fibra de madeira - uma variação muito notável da norma do andar, do olhar, do tocar, do falar, que possuo no meu íntimo porque sou corpo. Se além disso sou pintor, o que passará para a tela já não será somente um valor vital ou sensual, não haverá na tela somente "uma mulher", ou "uma mulher infeliz", ou "uma modista"; haverá o emblema de uma maneira de habitar o mundo, de tratá-lo, de interpretá-lo tanto pelo rosto como pela roupa, tanto pela agilidade do gesto como pela inércia do corpo, em suma, de uma certa relação com o ser. Mas esse estilo e esse sentido verdadeiramente pictural, se não estão na mulher vista - pois então o quadro já estaria feito -, são pelo menos atraídos por ela.

As experimentações em Composição Poética Cênica permitem que o ator investigue deliberadamente aquilo que, segundo Boesch (1991), acontece naturalmente em seu cotidiano. Ele tem acesso às diferentes coordenações de ação que configuram o seu campo pessoal de ação no mundo. O ator, na criação em tempo real, negocia, a todo instante, consigo mesmo, as projeções de futuridade de uma ação e a historicidade familiar dessa mesma ação. Ainda, negocia com os outros atores possíveis campos de atuação compartilhados e validados socialmente frente ao grupo. Assim, a criação teatral, como uma manifestação humana, atende a pelo menos 3 níveis de coordenação de ações: 1- no plano da concretude - coordenação espaço-temporal de diferentes ações; 2 - no plano pessoal - coordenação entre realização efetiva e intencionalidade pessoal da ação; 3- no plano interpessoal - coordenação entre a ação realizada e os desejos, por vezes discrepantes, dos envolvidos na ação.

No caso dos coletivos teatrais, as ações acabam direcionadas a um porvir que é assumido pelos integrantes do [grupo] como um porvir comum, ainda que seja efetivamente diferente para cada um. Nesse sentido, a experiência estética radicaliza a coexistência das temporalidades: os seres-atores não só compartilham o presente, como também um estado de futuridade, que, talvez, não chegue sequer a se tornar presente. (Sampaio, 2014, p. 143). 
Ou seja, aos poucos, a Composição Poética Cênica disponibiliza para os atores um espaço para testar seu potencial pessoal motor e simbólico de ação e de criação, em um trânsito entre o passado familiar, o futuro intencionado e o presente atual e virtual das relações. Na medida em que o ator se sente seguro para agir em direção aos seus anseios pessoais, mas também em direção aos desejos compartilhados de criação, ele experimenta paulatinamente a ampliação do seu poder de ação simbólica sobre o mundo, e com isso, a sua capacidade crescente de supor relações diferentes daquelas garantidas, em certo sentido, pela historicidade.

\section{Considerações finais}

Esta pesquisa teórico-empírica, que partiu de uma tentativa de resposta às questões apresentadas na introdução deste texto, levou-nos a compreender a Composição Poética (corpo-sonora) Cênica como um processo colaborativo que opera o campo estético a partir das qualidades de movimentos corporais e vocais e elabora nexos teatrais fundados em texturas imagético-sonoras polifônicas. As experimentações que resultaram desse processo de composição cênica, na esteira do que descrevemos na segunda parte da discussão deste artigo, fazem emergir processos de construção pessoal de conhecimento, que, por sua vez, potencializam novas dinâmicas de criação pessoal e coletiva.

Compreendemos que ao se permitir a esse processo, o ator explora seu poder de ação motora e simbólica sobre o mundo e realiza diversos trânsitos entre aquilo que deveria ser e aquilo que poderia ser cada uma das relações que estabelece com diversas materialidades no mundo com fins da criação artística. Com isso, vê crescer seu campo de intervenção sobre o mundo e, assim, se abre no mundo para novos modos de ser, capturado por esse mesmo mundo. Nessa direção, a criação teatral, ou melhor, o produto artístico, acaba por ser também, e talvez principalmente, a evidenciação de existências relacionais com qualidades específicas deliberadas que revelam modos pessoais de buscar no mundo respostas motoras e simbólicas às intenções pessoais.

O trabalho vocal, que ocupou boa parte deste texto e das nossas pesquisas, vem permitindo a observação fenomênica do que supomos do processo de formação pessoal e construção de conhecimento no sentido já exposto neste texto. Pelo menos dois aspectos merecem atenção, reiterativamente: 1- Foi realizada uma condução por parte dos diretores do espetáculo a partir de experimentações que partiam de sons naturais, de fácil emissão por parte dos atores, tidos por eles como familiares. Com o aumento da sensação de segurança por parte de cada ator em relação à sua materialidade vocal pessoal, investidas mais complexas passaram a ser realizadas, rumo à construção de um espaço simbólico-sonoro para o espetáculo; 2- Os elementos constitutivos da sonoridade do espetáculo estão postos pelos atores em cena desde o início da obra e ganham complexidade na medida em que o espetáculo se desenvolve. Ou seja, trata-se de levar à cena o trabalho de expansão por experimentação da potência simbólica sonora pessoal e grupal. Os atores, ao mesmo tempo, testam e reorganizam suas habilidades 
concretas de emissão sonora, e ampliam seu campo potencial de ação simbólica, na medida em que articulam novos contextos e nexos estéticos para aquilo que desenvolvem pessoal e coletivamente enquanto obra de arte.

Assim, podemos observar que a nossa proposta estética, ela mesma, acaba por refletir os pontos centrais das dinâmicas de construção de conhecimento na condução deste experimento artístico: o conhecimento é construído com referência naquilo que a pessoa toma como familiar e natural para si; a ampliação do poder de ação individual, que tomamos desde Merleau-Ponty e Boesch como uma forma de conhecimento, resulta da negociação de sentido coletivo e da coordenação de ações intra e intersubjetivamente.

Apesar de estar o ator sempre disposto ao trabalho a partir daquilo que julga familiar e que the permite avanços de exploração estética e artística, o contexto da cena não é vivido por ele como distante ou separado da vida cotidiana. Para um ator em atividade profissional, por exemplo, estar em cena ou em pesquisa para a cena é constante, ocupando boa parte de seu tempo no dia-a-dia. Assim, a exploração acional para a cena é igualmente uma exploração acional para a vida cotidiana. Se o cotidiano subsidia os investimentos cênicos, as explorações cênicas reorganizam as potencialidades simbólico-acionais dos atores. Portanto, se estamos interessados na formação do sujeito-artista devemos atentar para o fato de que as escolhas estéticas têm implicações sobre a existência cotidiana do profissional da cena. Nesse sentido, a pesquisa aqui realizada pode ser de grande valia, na medida em que investiga a um só tempo a experiência artística e a formação da pessoa que é artista.

\section{Referências}

BOESCH, Ernest. Symbolic Action Theory and Cultural Psychology. Springer: Berlim Heidelberg - Nova York, 1991.

LABAN, Rudolf. O Domínio do Movimento. Summus Editorial: São Paulo, 1978.

MERLEAU-PONTY, Maurice. Fenomenologia da Percepção. Martins Fontes: São Paulo, 2011. O Visível e o Invisível. Perspectiva, São Paulo, 2012.

O Olho e O Espírito. CosacNaiFy Portátil: São Paulo, 2013.

TRAGTEMBERG, Lívio. Música de Cena: dramaturgia sonora. Perspectiva, FAPESP: São Paulo, 1999.

SAMPAIO, Juliano Casimiro de Camargo. As Artes Cênicas e o Construtivismo Semiótico-Cultural em Psicologia - diálogos a partir da experiência corporal-estética em Composição Poética Cênica. Tese de Doutorado, Instituto de Psicologia, Universidade de São Paulo, São Paulo, 2014. 
SIMÃO, Lívia Mathias. Interação Verbal e Construção de Conhecimento: aspectos do diálogo pesquisador-sujeito. Psicologia: Teoria e Pesquisa, 8(2), pp. 219-229, 1992.

Recebido em 30/04/2014 Aprovado em 26/06/2014 